typical of a large number of others, and, as it is the constipation which gives the most trouble, it is the symptom for which the medical man is usually consulted. Here there is loss of tone not only in the abdominal muscles, but also atony of the intestinal walls, and our object must be to strengthen those parts. This is best attained by certain manipulations, which include circular movements, kneading, and tapotement or petrissage. The first procedure can be corried out either with one or both hands, and it is necessary that the abdominal walls should be slicrhtly relaxed, so that the intestines can be reached and acted directly on. But in a case of this nature, although abdominal massage will effect a great deal of good, it will not be productive of lasting benefit if we omit to massage the spine. The cause of the constipation is partly situated here; there is functional derangement of the cord, and until this is removed by mechanical stimulation it is hopeless to expect a complete cure. In these cases I have noticed that from the first day in which massage was commenced the excessive secretion of urea decreased, and after a week had disappeared altogether, leaving the urine perfestly normal. This is the first time that a similar observation has been made, althourh it has been admitted that galvanisation of the spine has a similar effect where an atonic condition of the spinal cord is found to exist.

CASE 3.-This case is typical of that large class of both sexes who enjoy good health and suffer no inconvenience, except that occasioned by constipation. The abdominal walls were flabby and pendulous, and characterised by great weakness. In cases of this sort the manipulations must be directed towards strengthening the abdominal walls, and for this purpose the abdominal recti must be forcibly separated by the finger-tips inserted deeply along the linea alba. This procedure must be followed by the circular movement already indicated. At the same time, the patient is recommended to take deep inspirations for the purpose of strengthening the diaphragm.

Massage is also extremely useful in the very obstinate constipation so frequently met with amongst infants. I have known it prove successful after the failure of the usual remedies. Few applications are needed, generally not more than a dozen, and the time occupied by each should be about ten minutes.

Liverpool.

\section{Clinical 就otes:}

\section{MEDICAL, SURGICAL, OBSTETRICAL, AND THERAPEUTICAL.}

\section{NUX VOMICA IN CARDIAC FAILURE.}

\section{By A. Bowie, M.D., C.M., L.R.C.P. ED.}

I would like to draw attention to the value of nux vomica in the above condition. During the fog which ushered in this year I was asked to see two very marked cases, in each of which death must have speedily occurred but for timely relief.

The first case, a lady aged forty-two, had suffered more or less for three years with bronchitis and mitral stenosis. Wher I saw the patient her face was pale and anxious and her lips livid ; the breathing was short and rapid, and pulsation at the wrist could scarcely be felt; nausea and occasional vomiting of mucus were present, and there was dread of taking food or lying down. The condition had commenced ten hours previously with epigastric pain; but while the other symptoms had increased in severity, the pain seemed to have remained stationary. I prescribed tincture of nux vomica in small doses every half-hour for four doses, then every hour, and there was rapid return to the ordinary condition, although the surroundings and the fog remained for some time as they were before.

The second case was that of a gentleman aged forty-nine, who had suffered for some years from mitral regurgitation and persistent although mild bronchitis. Exposure had induced an attack of left lobar pneumonia, which had been running the usual course until the fifth day, when a dense fog occurred in his district. Upon examination his pulse was found to be weak, rapid, irregular, and easily collapsible; his extremities were cold, with clammy perspira- tion all over his body, and beads of the same upon his livid countenance. He complained of intense pain over the apex of the heart, and his brenthing was short and hurried. There was no sickness. His condition had been gradually taking on the above aspect for four or five hours. He had been taking digitalis for two days previously to the attack. This we at once stopped, and substituted tincture of nux vomica, as in the other case, with the result that the patient gradually rallied, and in twenty-four hours had lost his cardiac pain entirely.

I think there can be no doubt that the admistration of the nux vomica in the above cases stimulated the motor centres and the ganglionic system to increased activity, and rescued the patients from the consequences of obstructed pulmonary circulation and engorgement of the right heart.

Harley-street, W.

\section{DISLOCATION OF THE META'TARSUS.}

BY H. LiTTLEWOOD, F.R.C.S. ENG.,

RESIDENT SURGIC'L OFFICER, LEEDS GENERAL INFIRMARY.

IN ThE LANCET of Dec. 1st, in the report of the Leeds and West Riding Medico-Chirurgical Society, Mr. Atkinson records a case of dislocation of the metatarsus. Since then Mr. Atkinson has had a second case of a similar nature.

Jane C_- aged thirty-one, was admitted to the Leeds Infirmary on Dec. 2nd, at 8 P.M. At 5 P. M. she had fallen off a chair on which she was standing on to her left foot. It rave her considerable pain, and she fainted. On looking at the foot she noticed there was " a lump with a hollow behind it" on the back of the foot. On examination, the left foot was found to be everted, the metatarsus forfining a slight angle with the tarsus. There was a good deal of swelling on the dorsum of the foot; the extensor tendons were prominent; the hollow of the sole was less marked than on the opposite side. On manipulation of the dorsum, the articular surfaces of the bases of the four outer metatarsals conld be distinctly made out above the level of the tarsus (about one-third of an inch). The big toe was not dislocated from its cuneiform bone, but the internal cuneiform bone was dislocated upwards from the navicular bone, forming a distinct prominence on the inner side of the dorsum of the foot. The measurenent from the heel to the tip of the hallux was the same as on the opposite side; from the external malleolus to the tip of the fifth toe it was a third of an inch less. Under chloroform the dislocation was easily reduced by making traction, and at the same time pressing downwards on the bases of the metatarsals. No crepitus was felt.

This case differs from the one previously recorded in not having all the metatarsal bones dislocated upwards, the big toe not being dislocated, but the internal cuneiform dislocated upwards from the navicular bone. The dislocation was not complete in either case. In the former case a suspicion of crepitus was felt on reduction, sugresting possibly a fracture. In this case no crepitus was felt. In both cases reduction was easy, the foot readily going back into its natural position, in the former case without, and in the latter case with, an audible snap. The amount of swelling consequent on the injury soon disguises the deformity, and, I think, cases may be very easily overlooked, unless seen within a short interval after the injury. Leeds.

\section{CASE OF CRANIOTOMY.}

By HaRRy Eugene HaCKeTT, M.R.C.S., L.R.C.P.LoNd., MEDICAL OFFICER, GORTON DISTRICT, CHORITON UNION.

TuE paper read by Dr. Donald at a recent meeting of the Obstetrical Society on Craniotomy induces me to forward notes of a case recently under my care, in which the method suggested by him was used successfully. The case is also interesting by reason of Dr. Donald having previously performed craniotomy whilst he was resident at St. Mary's, and he has kindly furnished me with notes, from which I extract the following.

Mary E. L_一, aged seventeen; primipara; duration of labour forty-eight hours. On July 25 th, 1886, the patient was brought to the hospital in a cal. The forceps having been tried without success, version was performed. On ad. mission the patient was much exhausted. There was a 
generally contracted flattened pelvis (C.V. $=2:$ inches). The uterus was firmly contracted, with the head above the brim. The cephalotribe was applied and the head crushed laterally. The cephalotribe was reapplied, the head having been rotated so as to crush in different diameters; then by means of traction with the finger in the scalp, and supra-pubic pressure, the head came through. The patient made a good recovery. On Dec. 3rd, 1888, a message was received at 1.30 A.M., a midwife having been in attendance from 10 P.M. On examination, the head was found presenting, the funis prolapsed, and no pulsation of cord. The membranes were ruptured at about 11 A.M. by the midwife. Finding the pelvis greatly contracted, I decided to turn, thinking that the head might be got through. My friend, Dr. B. W. MacArthur, kindly assisting me, the patient being under the influence of chloroform, I, with considerable difficulty, managed to turn. The forceps were applied, without any result. I then (the occiput being backwards and the body drawn forwards) perforated through the occiput and endeavoured to extract; but, failing to do so, I perforated through the mouth, and with the assistance of traction the head easily came through. The placenta followed quickly. For four days the patient made good progress, but unfortunately on the fifth day she had a rigor, peritonitis supervened, and death occurred on the seventh day.

The ease with which delivery was accomplished after perforation through the mouth, the other method having failed, should ensure trial of this method in similar cases. Gorton.

\section{dy a ditrox}

OF

\section{HOSPITAL PRACTICE, BRITISH AND FOREIGN.}

Nulla autem est alia pro certo noscendi via, nisi quamplurimas et mor. borum et dissectionum historias, tum aliorum tum proprias collectas habere, et inter se comparare.-MongagN De Sed. et Caus. BIorb., lib. iv. Procemium.

\section{ST. THOMAS'S HOSPITAL.}

CONICAL BULLET WOUND PASSING ACROSS THE SKULL FROM ONE TEMPLE TO THE OTHER; RECOVERY, BUT WITH LOSS OF VISTON OF THE RIGHT

EYE; REMARKS.

(Under the care of Mr. Sroney JonEs.)

WE drew attention to this unusual case of bullet wound of the head ${ }^{1}$ soon after its occurrence, and we now publish it in full. Such wounds are rare even in military practice. In the British returns after the Crimea, the bullet wounds accompanied by injury to one or both eyes are stated to have been forty-five in number, with three deaths. During the American war, in which the rifle bullet was conical, a large number of such injuries were met with; they are divided into those in which the wound involved both orbits with damage to the eyes, and those in which only one orbit and its contents received injury. Of the former there are thirty-nine cases, eleven of which were fatal. The conical bullet caused more severe and extensive local damage. Some of these cases ${ }^{2}$ much resemble the one recorded by Mr. Sydney Jones. A soldier, aged twenty, was wounded by a conical bullet, which entered immediately behind the outer angle of the right eye, passed through the orbital plate at the junction of the malar and frontal bones, through the greater wing of the sphenoid, and emerged at a point corresponding to the wound of entrance, which was about half an inch in diameter. The ball apparently passed beneath the cribriform plate of the ethmoid. The optic nerves on each side were severed and the lacrymal bones destroyed; the eyes were also irretrievably damaged. Profuse suppuration and restlessness occurred. Sequestra were removed. A salty discharge from the left eye was present for a time after the seventeenth day. He suffered from anosmia and had night sweats. In the case of a man aged

1 The LaNCEx, 1888, vol. ii., p. 728.

2 Surgical IIistory of the United States War, vol. i. twenty-four, the bullet entered above the left zygoma and passed out of the head at the outer and upper part of the right orbit, destroyed both eyes, produced anosmia, and later on sequestra required removal. In another the bullet passed through transversely at a point corresponding to an inch and a half from the angle of the eye ; in several others it took a similar direction, and the wound followed a similar course, producing complete loss of sight and followed by suppuration. In a man aged twenty-one, a conical ball entered at the external angle of the right eye, passed through the nose and lodged, destroying the right eye entirely. Inflammation and loss of sight in the left eye followed. The question as to the development of sympathetic ophthalmia in the remaining eye, when only one is destroyed, is important with regard to the prognosis and treatment. Out of ninetyone cases where one eye was destroyed, the sight of the remaining eye was impaired or it was sympathetically affected. In one case mental aberration developed, from which the patient slowly recovered. In several, small sequestra required removal, and in one treatment for fixation of the jaws was required. Secondary hæmorrhage does not appear to have been very frequent in this kind of wound, though the vascularity of the bones of the face has rendered wounds of them specially liable to troublesome hamorrhages, whether prinary or secondary. For the notes of the following case we are indebted to Mr. Arthur Lankester.

A. W-, aged forty-six, a strong, somewhat plethoriclooking man, was admitted on October 5th with a bullet wound in his right temple. He had been found about an hour before in his bedroom lying unconscious, with a five-chambered revolver close by his side, one chamber of which had recently been discharged. When first found, he was bleeding somewhat profusely at the mouth and nose.

On admission, the man was in a semi-conscious state, breathing heavily, but with a fairly good pulse. There was a small round hole in the region of the right temporal fossa, one inch behind the orbital margin and lialf an inch above the zygomatic arch. From this hole blood was trickling, but in inconsiderable quantity. The skin around the wound was blackened. There was slight bleeding from the mouth and nose, none from the ears. Over the left malar bone, and below it, there was some swelling of the parts, and, on careful examination, crepitus was obtained, and a small hard body conld be felt immediately below the zygomatic process of the bone. There was no aperture of exit of the bullet. The whole face was congested, and there was great ecchymosis of eyelids, especially on the right side. Half an hour afterwards he was perfectly conscious, and answered questions rationally. He complained of thirst and of pain across the frontal region. On examining the eyes, the right one showed marked conjunctival chemosis; the pupil was dilated and inactive to light; vision was lost, perception even of light being absent. With the left eye the patient could see a hand heid up before him, but was unable to distinguish the separate fingers; the left pupil was also dilated and inactive to light.

One hour after admission chloroform was administered and Mr. Sydney Jones explored the wound. A crueial incision, through skin and muscle down to the bone, was made, having the bullet wound in its centre, and, hæmorrhage having been arrested, a finger was inserted, when it was found that there was no splintering of the bone, but a clear round aperture through which the bullet had passed. The wound, the central part of which was black and charred by the passage of the bullet, was thoroughly cleansed by means of a solution of chloride of zinc, forty grains to the ounce, and was covered temporarily whilst an examination of the left side of the face was proceeded with. An antero-posterior incision (of about an inch and a half in length) was made immediatelyover the point where the small hard body above mentioned was to be felt. The left malar bone and zygomatic arch were found to be much splintered but only one or two small fragments were sufficiently detached to be removed. Embedded firmly in the bone, but projecting somewhat from it, the bullet was felt, and, after a short time, was extracted by forceps. It had preserved its cylindrical form, but showed deep spiral grooves on its surface, and, impacted in these grooves, small particles of bone could be seen. Mr. Sydney Jones then returned to the examination of the entrance wound, and succeded in passing a bullet probe through from one aperture to the other, so as to transfix the head. The probe was not tightly 